\title{
Factors Affecting Destination Choice in Medical Tourism
}

\author{
Haşim Çapar ${ }^{1 *}$, Özgür Aslan² \\ ${ }^{1}$ Department of Health Management, Faculty of Health Sciences, Istanbul Sabahattin Zaim University, Istanbul, Turkey \\ ${ }^{2}$ Department of Health Management, Faculty of Health Sciences, Istanbul-Cerrahpasa University, Istanbul, Turkey \\ Corresponding Author: Hasim Capar, PhD Candidate, Research Assistant, Department of Health Management, Faculty of \\ Health Sciences, Istanbul Sabahattin Zaim University, Istanbul, Turkey. Tel: +90-02126928894, Fax: +90-02126938229, \\ Email: hasim.capar@izu.edu.tr
}

Received January 25, 2020; Accepted April 27, 2020; Online Published May 31, 2020

\begin{abstract}
Introduction: Although many factors can affect the choice of destination in medical tourism, some factors are indispensable to medical tourists and medical tourism. The aim of this study was to analyze important factors affecting the selection of a destination by potential medical tourists.

Methods: This descriptive, cross-sectional study, conducted in Turkey, included a population of 1700 people and a sample size of 317 people selected through purposive sampling. Values were evaluated with a $95 \%$ confidence interval and 0.05 standard error. A value of $P<0.05$ was considered statistically significant. The medical tourism scale and a demographic information form were used in data collection. Exploratory factor analysis (EFA), confirmatory factor analysis (CFA), and path analysis were used as statistical methods. Analyses were made using IBM SPSS-AMOS 25.0.

Results: In this study, $56.5 \%$ of the participants were male and $43.5 \%$ were female. The factors affecting the selection of medical tourism destinations were determined to be, in order of importance, accessibility of health care service $(\overline{\mathrm{X}}=4.68 \pm 1.073)$, level of security and safety $(\bar{X}=4: 57 \pm 1.122)$, quality of health care service $(\bar{X}=4: 39 \pm 1.129)$, level of hygiene $(\bar{X}=4.16 \pm 1.381)$, potential of savings-low cost $(\overline{\mathrm{X}}=4.07 \pm 1.447)$, and tourism opportunities $(\overline{\mathrm{X}}=4.02 \pm 1.540)$.

Conclusion: It is thought that the current study will make a serious contribution to the field of medical tourism both in practice and in theory.

Keywords: Medical Tourism, Decision-making, Turkey, Medical Marketing, Treatment Abroad
\end{abstract}

Citation: Çapar H, Aslan O. Factors affecting destination choice in medical tourism. Int J Travel Med Glob Health. 2020;8(2):80-88. doi:10.34172/ ijtmgh.2020.13.

\section{Introduction}

Medical tourism has created a new financial sphere as an alternative source of funds with a rapidly growing market share worldwide. Developing, developed, and even underdeveloped countries have made investments to increase their medical tourism market. It is a known fact that the health systems of most of the countries that want to invest in and increase their share of the medical tourism market are not good. Nevertheless, the fact that many countries with poor health systems invest in this area is evidence that medical tourism is seen as a very important business opportunity.

Medical tourism is considered as a strategic alternative tourism resource with many benefits, particularly economic ones, and has gained importance in recent years. ${ }^{1,2}$ This industry has become an area of major competition with many destinations, especially in developing countries, and is expected to develop rapidly. ${ }^{3,4}$ Many factors affect potential medical tourists' intentions to participate in medical tourism and the destinations they choose..$^{5-8}$ Choosing a destination comprises a 3-stage process: (1) research before mobility; (2) satisfaction and impressions during mobility; and (3) services provided after medical tourism activity.,9

In 2017, the medical tourism market was $\$ 15.5$ billion worldwide and estimated to be $\$ 28$ billion by the end of $2024 .^{10}$ A phenomenon with a market of this size is an important business opportunity for all countries. ${ }^{11-14}$ Among the many factors that affect the choice of destinations in medical tourism, some are indispensable to medical tourists and medical tourism. ${ }^{6,8}$ Entrepreneurial countries that want

Copyright $\odot 2020$ The Author(s). This is an open-access article distributed under the terms of the Creative Commons Attribution License (http:// creativecommons.org/licenses/by/4.0), which permits unrestricted use, distribution, and reproduction in any medium, provided the original work is properly cited. 
to get a share of this market want to know the important factors effective in choosing a medical tourism destinations that make up this market. ${ }^{6,8,15-17}$ Some important factors, such as environmental factors, hygiene level, safety and security issue, easy transportation, government guarantee, and posttreatment service, have been identified. ${ }^{2,6,18}$

Although these factors vary from culture to culture, some are important for all citizens of the world. ${ }^{19-22}$ When looking at mobility in medical tourism, a trend is seen from developed countries to developing countries which shapes the factors that influence the choice of medical tourism destinations. ${ }^{23-28}$ Because medical tourists in developed countries are unable to move the elderly with chronic diseases, or health services are too expensive, or some medical treatments are not covered by insurance, or health insurance does not cover all citizens, medical tourists are directed to other countries. ${ }^{29-33}$

Other factors affecting destination choice include low costs, a well-proven or renown team, cultural proximity, environmental factors, good accommodations, importance given to privacy, geographic proximity, quality of healthcare, security, natural factors, entertainment, improved medical technology, thinking about relatives of the patients, state guarantee, the existence of language services, considering the food-beverage culture of medical tourists, providing religious services, providing halal environments, medical specialization, giving a sense of trust to patients, providing post-treatment services, the attitude of insurance companies or agencies. ${ }^{6,11-13}$

The theoretical model used in this study was designed with a conceptual framework and the 3 concepts of medical tourism, destination choice, and destination image.

In determining the model used for the current study, each concept was used to include all the factors affecting the choice of destinations in the medical tourism as much as possible by including a series of variables. ${ }^{2}$

Medical tourism, the first concept in the study model, is defined in many ways; however, within the framework of the model of this study, medical tourism is defined as patients who receive healthcare services in other countries and are willing to take all possible risks that may occur with this decision. ${ }^{34}$ There is a bidirectional factor affecting the mobility of medical tourists. This bi-directionality can be considered as mandatory and voluntary factors that may influence the decision of a potential medical tourist. Mandatory factors include the absence of the desired medical treatment in the home country, the high expense of health services, and long waiting lists, and low quality medical treatment in the home country, among others. Voluntary factors include geographical proximity; the presence of sea, sand, and sun advantages; similarities of language and culture; nightlife activities; etc. . $^{35,36}$

Another concept that forms the model of the current study is destination choice. The choice of destination involves a list of stages, with motivation at the top. Two important factors that increase the motivation of potential medical tourists are quality healthcare and relatively cheap healthcare. ${ }^{6,18}$ After deciding on a treatment, medical tourists research possible destinations and then select one. Although the main purpose of medical tourism is to receive medical treatment, environmental factors, hygiene, security issue, easy transportation, government guarantee, post-treatment service are among the determining factors in destination selection. ${ }^{18}$

One important variable is destination image, defined as the information, impression, prejudice, and emotional thoughts of potential medical tourists regarding certain destinations. ${ }^{37}$ In short, image is a factor affecting medical tourists' short and long memories and their choice of destination. ${ }^{38}$

The current study aimed to analyze important factors affecting destination choice of foreign medical tourists, their motivation and behavior regarding medical tourism preferences, and their reasons for choosing Turkey as a medical tourism destination. Accordingly, the effects of 6 variables thought to affect medical tourism destination choice were investigated. Figure 1 briefly illustrates the purpose of this study.

\section{Methods}

Measurements and Questionnaire

A questionnaire was used as the data collection method. Jotikasthira $^{6}$ confirmed the reliability and validity of the questionnaire. Only 2 parts of the questionnaire consisting of 5 sub-sections were used as the medical tourism scale. Moreover, the population of the current study and that of the study from which the scale was taken differed. Therefore, to insure the reliability of the results, explanatory factor analysis (EFA) and confirmatory factor analysis (CFA) were performed to verify the construct validity and the goodness of fit of the scale..$^{39,4041}$ Data collection was conducted between September 2017 and March 2018.

Population, Sampling, and Inclusion and Exclusion Criteria This study considered a total accessible population of 1700 people searching for information about Turkey as a medical tourism destination through external resources such as websites, social media platforms, and medical tourism association sites and who could read and understand English.

The questionnaire used for this study consisted of 2 parts with 30 questions in total. The first part comprised 3 questions about the gender, country of residence, and annual income of the participants. The second part comprised a 5 -point Likert-style medical tourism scale ${ }^{6}$ consisting of six

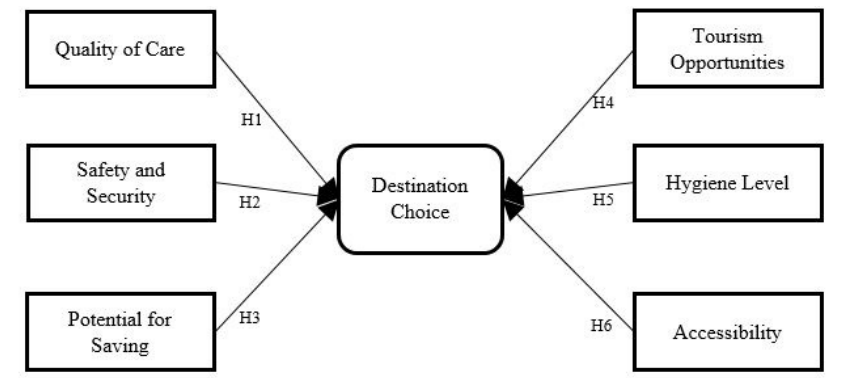

Figure 1. Proposed Conceptual Model Explaining Factors Influencing Medical Tourism Destination Choice. 
subsections: quality of care $=7$ questions, safety and security $=6$ questions, potential for saving $=6$ questions, tourism opportunities $=4$ questions, hygiene level $=2$ questions, and accessibility $=2$ questions. All items in the scale were positive. The highest and lowest possible scores were 135 points $(27 x 5)$ and $27(27 \times 1)$, respectively. A higher score was indicative of the importance of the relevant factor, and a lower score indicated that the relevant factor was insignificant.

Purposive sampling (also known as selective or subjective sampling) was used in this study. In this sampling method, researchers select the population that meets their own criteria for specific purposes as a sample. ${ }^{42,43}$ Inclusion criteria for the current study were a written request for information on Turkey as a medical tourist destination on the site used for data collection; the ability to read and write in the English language, and the potential of the medical tourist to visit Turkey. Persons seeking medical tourism information about Turkey who were physicians, healthcare workers, or businesspersons and those who could not read or write in English were excluded from the study. A total of 1700 people were identified as potential participants in the study, and attempts were made to reach all of them. Of that number, 854 agreed to participate, and questionnaires were distributed to them; only 337 surveys were completed by the participants, of which only 317 were completed correctly. Therefore, the sample size of this study was 317 people.

\section{Study Type, Data Collection Method, and Data Analysis}

Result-binding research is done to test an estimate or a hypothesis. ${ }^{44}$ In this study, descriptive, cross-sectional, and causal research subtypes the causal-comparison model of quantitative research were used.

To collect data, social media accounts, blogs, and websites of medical tourism associations promoting different medical tourism destinations were identified, and the platforms for data collection were determined. Then, a message was sent via social media account or e-mail to the identified potential medical tourists who met the study's inclusion criteria asking for voluntarily participation in the study. The online questionnaire was sent to those who responded affirmatively. A second message was sent to those who did not respond to the questionnaire within a week. This step was repeated 3 times. If no response was received after 3 messages, no further communication was sent. After applying the above procedures, the data was made suitable for research.

EFA was performed to determine the factors in the scale. CFA and structural equation modeling were performed to test the proposed model. EFA was carried out using SPSS 25 software, the principal components analysis (PCA) technique, and the direct oblimin rotation method. The suitability of EFA was explained by the Kaiser-Meyer-Olkin (KMO) sample proficiency test and Barlett's sphericity test results. A KMO value of 0.60 or higher seems sufficient for the implementation of EFA. Bartlett's sphericity test was considered statistically significant for values less than 0.05 . Sub-dimensions were extracted for eigenvalues greater than $1 .^{39-41,45}$
Generally, factor loads should be greater than 0.50, which is considered the threshold value. ${ }^{46} \mathrm{CFA}$ ensures that the current data collection tool can be used in different situations and in the structural situation that occurs with EFA. ${ }^{40}$ The CFA results for this study were obtained with AMOS 25 software. Accepted values for CFA were $\chi^{2} / d f \leq 5$, RMSEA $\leq$ 0.010 , CFI $\geq 0.90$, and NFI $=\geq 0.90 . .^{39,47}$

\section{Results}

\section{Participant Profile}

Participant profiles showed that male participants (56.5\%) numbered slightly higher than female participants (43.5\%). The home countries of the participants included Germany (16.1\%), United Kingdom (14.2\%), United Arab Emirates (12.9\%), Iraq (7.3\%), Iran (6\%), Russia (5.7\%), the United States (4.7\%), Australia (4.4\%), Albania (3.8\%), Qatar (3.2\%), and others (21.8\%). The annual income levels of the participants were \$60001-100000 (38.2\%), \$30001-\$60000 $(25.6 \%)$, and $\$ 200001$ or higher (2.5\%).

\section{Findings Related to Exploratory Factor Analysis}

EFA, with the PCA technique and the direct oblimin rotation method, was used to determine what important factors were included in the scale. The analysis results were somewhat similar to the validity and reliability study conducted by Jotikasthira. ${ }^{6}$ After the low factor load items $(<0.40)$ and cross-loadings were removed, only 27 of the 36 developed items remained. ${ }^{48}$ These 27 items constituted a 6 -factor structure. To perform exploratory factor analysis, a KMO value of 0.60 or higher must be statistically significant. Both assumptions were provided for this study (KMO $=0.919$, Barlett's test of sphericity <0.05) (Table 1$).{ }^{49}$ According to the EFA results, the scale consisted of 6 sub-dimensions. This 6 -factor structure explained approximately $61.761 \%$ of the total variance. In addition, the eigenvalue of each factor was greater than 1 .

Quality of care, the first factor with the highest explained variance $(16.280 \%)$ constituted a 7 -item structure. Safety and security, the second factor with the highest explained variance (13.769\%), constituted a 6 -item structure. The third factor, saving potential, had $13.194 \%$ of the total explained variance and a six-point structure. Tourism opportunities had the fourth highest explained variance (8.835\%) and constituted a 4-point structure. The fifth factor, hygiene level, captured $5.359 \%$ of the total explained variance. Accessibility formed a 2-item structure and accounted for $4.324 \%$ of the total explained variance. The factor load of each of the 27 items was over 0.50 , which was considered the threshold value. ${ }^{50}$ Alpha coefficient values, which were expected to be 0.70 or above (the threshold value), ${ }^{51}$ were $0.893,0.848,0.837,0.800,0.735$, and 0.731 for factors one through six, respectively. Therefore, this structure had reliable results. Finally, skewness and kurtosis values were evaluated for normality, linearity, and homogeneity of the data before applying the model. Skewness and kurtosis values should be between -2 and +2 for the data to show normal distribution. ${ }^{47}$ The skewness values in this study 


\section{Factors}

Loadings Eigenvalues Explained Variance Cronbach's

Factor 1: Quality of Care

(\%) Explained (\%)

QUA1: "My ideal medical tourism destination has various hospital that are internationally accredited by world reputable institutions including JCIO (Joint Commission for Accreditation of Health Care Organizations)."

$16.280 \quad 16.280$

QUA2: "My ideal medical tourism destination has many hospitals that are affiliated with

reputable medical institutions and school."

0.834

QUA3: "My ideal medical tourism destination has many hospitals that are equipped with the world's most sophisticated medical equipment."

8.103

16.280

6.280

QUA4: "My ideal medical tourism destination has many international standard hospitals specializing in my desired treatments."

QUA5: "My ideal medical tourism destination has various hospitals that guarantee the results of the treatment and are willing to legally abide by relevant laws."

0.804

0.800

0.782

0.700

0.509

standards with board certified doctors and surgeons."

QUA7: "My ideal medical tourism destination has many hospitals that meet international standards and have high treatment success rates."

\begin{tabular}{lll}
\hline Factor 2: Safety and Security & 3.879 & 13.769 \\
\hline SAF1: "My ideal medical tourism destination is safe to travel to by oneself." & 0.716 \\
\hline SAF2: "In my ideal medical tourism destination is safe to walk on the street by oneself." & 0.682 \\
\hline SAF3: "My ideal medical tourism destination has low crime rates." & 0.681 \\
\hline SAF4: "My ideal medical tourism destination is not a target for terrorist attacks." & 0.648 \\
\hline SAF5: "My ideal medical tourism destination has a safe environment." & 0.623 \\
\hline SAF6: "My ideal medical tourism destination is politically stable." & 0.620 \\
\hline Factor 3: Potential for Saving & 0.837 \\
\hline
\end{tabular}

SAV1: "My ideal medical tourism destination provides my desired medical treatment at a lower cost compared to other destinations."

0.792

SAV2: "My ideal medical tourism destination provides the same medical treatments at a much lower cost than my home country."

0.770

SAV3: "My ideal medical tourism destination has a much lower cost of living compared to my home country."

SAV4: My ideal medical tourism destination can be accessed from my home country at a low cost."

0.685

0.624

SAV5: "My ideal medical tourism destination provides accommodations at an affordable cost."

SAV6: "My ideal medical tourism destination offers lower overall costs when combining the costs of medical treatments and all other travel costs."

0.620

\begin{tabular}{|c|c|c|c|c|c|}
\hline Factor 4: Tourism Opportunities & & 1.162 & 8.835 & 52.072 & 0.800 \\
\hline OPPORT1: "My ideal medical tourism destination has wonderful scenic beauty." & 0.773 & & & & \\
\hline OPPORT2: "My ideal medical tourism destination has beautiful beaches." & 0.687 & & & & \\
\hline OPPORT3: "My ideal medical tourism destination has good shopping facilities." & 0.664 & & & & \\
\hline OPPORT4: "My ideal medical tourism destination has authentic historical sites." & 0.647 & & & & \\
\hline Factor 5: Hygiene Level & & 1.034 & 5.359 & 57.437 & 0.735 \\
\hline $\begin{array}{l}\text { HYG1: "My ideal medical tourism destination has a level of hygiene similar to that of my own } \\
\text { country." }\end{array}$ & 0.796 & & & & \\
\hline HYG2: "My ideal medical tourism destination has no epidemic diseases." & 0.710 & & & & \\
\hline Factor 6: Accessibility & & 1.005 & 4.324 & 61.761 & 0.731 \\
\hline ACCESS1: "My ideal medical tourism destination has direct flights from where I live." & 0.672 & & & & \\
\hline $\begin{array}{l}\text { ACCESS2: "My ideal medical tourism destination is at a convenient proximity to my home } \\
\text { country." }\end{array}$ & 0.523 & & & & \\
\hline
\end{tabular}

$\mathrm{KMO}=.919$, Bartlett's test $\mathrm{Sig}=0.000$

Total explained variance $=61.761 \%$

Total $\alpha=0.807$

Abbreviations: QUA, care quality; SAF, security and safety; SAV, saving potential; OPPORT, tourism opportunities; HYG, hygiene level; ACCESS, accessibility. 
were between -0.987 (standard error $[\mathrm{SE}]=0.137)+0.368$ $(\mathrm{SE}=0.137)$. The kurtosis values also ranged from -0.900 $(\mathrm{SE}=0.273)$ to $+0.910(\mathrm{SE}=0.273)$. In summary, the data carried normality, homogeneity of variance, and linearity assumptions were suitable for analysis.

\section{Findings Related to Confirmatory Factor Analysis}

CFA should be used to verify the validity of the original structure of a previously developed scale related to any subject that is to be used on a different subject or sample. ${ }^{52}$ Table 2 presents the CFA findings for this study. The fit values of the model regarding the structure obtained with CFA were: $\chi^{2}=472.407, \mathrm{df}=309, \chi^{2} / \mathrm{df}=1.529, P<0.000$, $\mathrm{RMSEA}=0.041, \mathrm{CFI}=0.954$ and NFI $=0.902$. The results indicated that the data was consistent with the model. ${ }^{53}$ Furthermore, the reliability results, which ranged from 0.705 to 0.898 for composite variables, were above the critical value of 0.60 , indicating that the model had good reliability. ${ }^{54}$ In addition, average variance extract (AVE) values were between 0.509 and 0.561 , all higher than the 0.50 threshold. Structure validity analysis showed that the AVE values were higher than the square correlation values (Table 3$).^{50}$ The sixfactor structure was proven to be valid and reliable with CFA values (Figure 1).

Results of Path Analysis

Path analysis (PA) was conducted to test the study's hypotheses. According to the results, the data compatibility was quite good. Goodness of fit values were: $\chi^{2}=1130.502, \mathrm{df}$ $=508, \chi^{2} / \mathrm{df}=2.225, P<0.000, \mathrm{RMSEA}=0.063$, CFI $=0.902$, $\mathrm{IFI}=0.929$, TLI $=0.921, \mathrm{AGFI}=0.819$. Table 4 and Figure 2 show the PA results. The analysis results revealed statistically significant positive relationships between quality of care and destination choice ( $\mathrm{H} 1: \beta$ quality of care $->$ affective $=0.351$, $\mathrm{t}=3.553, P<0.01$ ), safety and security and destination choice $(\mathrm{H} 2: \beta$ safety and security $->$ destination choice $=0.379, \mathrm{t}=$ 4.568, $P<0.01$ ), potential for saving and destination choice $(\mathrm{H} 3: \beta$ potential for saving $->$ destination choice $=0.278, \mathrm{t}=$

Table 2. Results of Confirmatory Factor Analysis

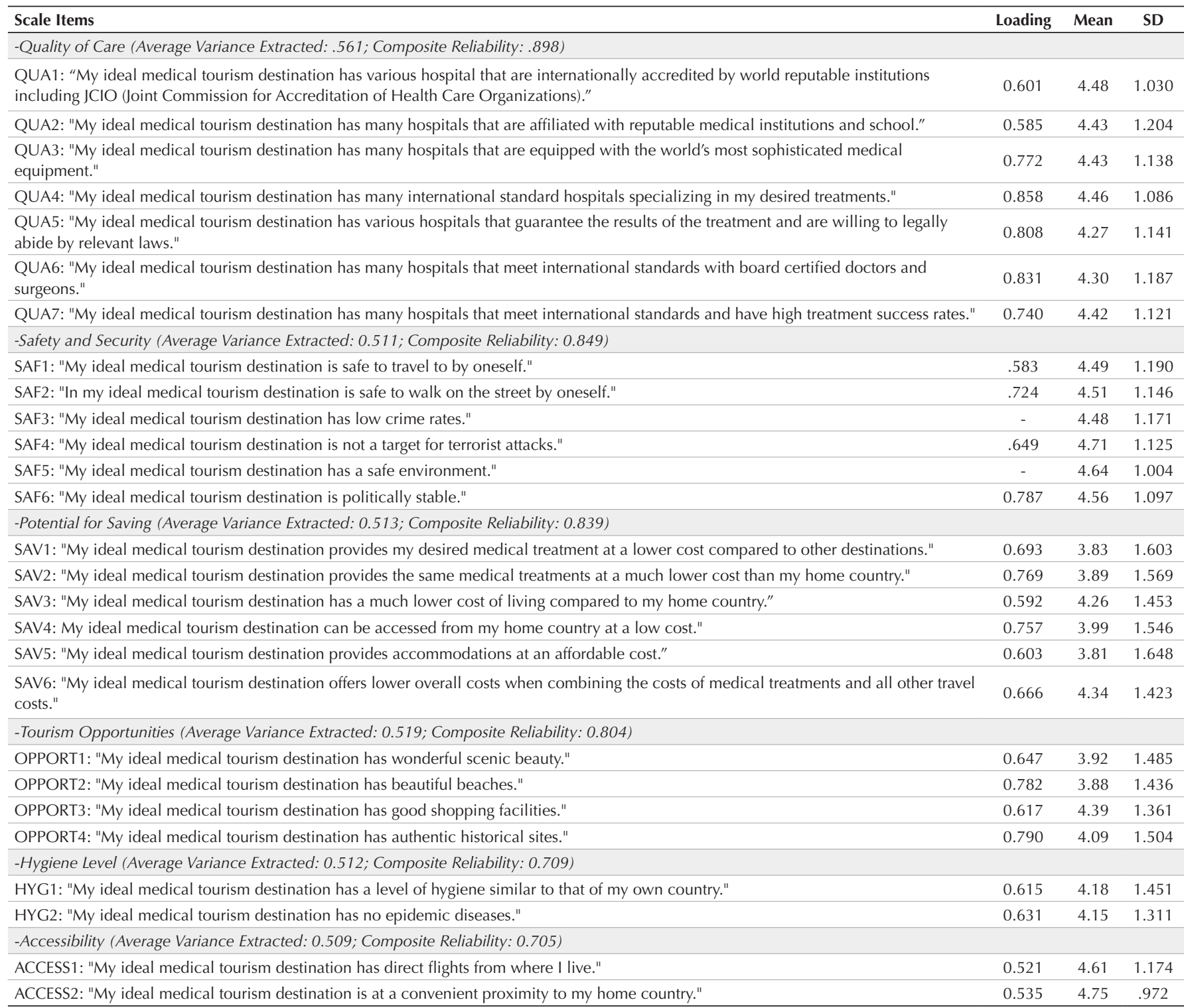

Abbreviations: QUA, care quality; SAF, security and safety; SAV, saving potential; OPPORT, tourism opportunities; HYG, hygiene level; ACCESS, accessibility. 
Table 3. Results of Correlations Factors

\begin{tabular}{|c|c|c|c|c|c|c|}
\hline Constructs & 1 & 2 & 3 & 4 & 5 & 6 \\
\hline \multicolumn{7}{|l|}{ 1.Care Quality } \\
\hline 2.Security and Safety & 0.415 & & & & & \\
\hline 3.Saving Potential & 0.536 & 0.216 & & & & \\
\hline 4. Tourism Opportunities & 0.247 & 0.435 & 0.163 & & & \\
\hline 5.Hygiene Level & 0.347 & 0.058 & 0.327 & 0.116 & & \\
\hline 6.Accessibility & 0.333 & 0.046 & 0.049 & 0.105 & 0.039 & \\
\hline SD & 0.881 & 0.847 & 1.144 & 1.144 & 1.151 & 0.898 \\
\hline
\end{tabular}

$\chi^{2}=472.407, \mathrm{df}=309, \chi^{2} / \mathrm{df}=1.529 ; P<0.000, \mathrm{RMSEA}=0.041 ; \mathrm{CFI}=0.954 ; \mathrm{NFI}=0.902 ; \mathrm{IFI}=0.955 ; \mathrm{NNFI}=0.908 ; \mathrm{AGFI}=0.880$.

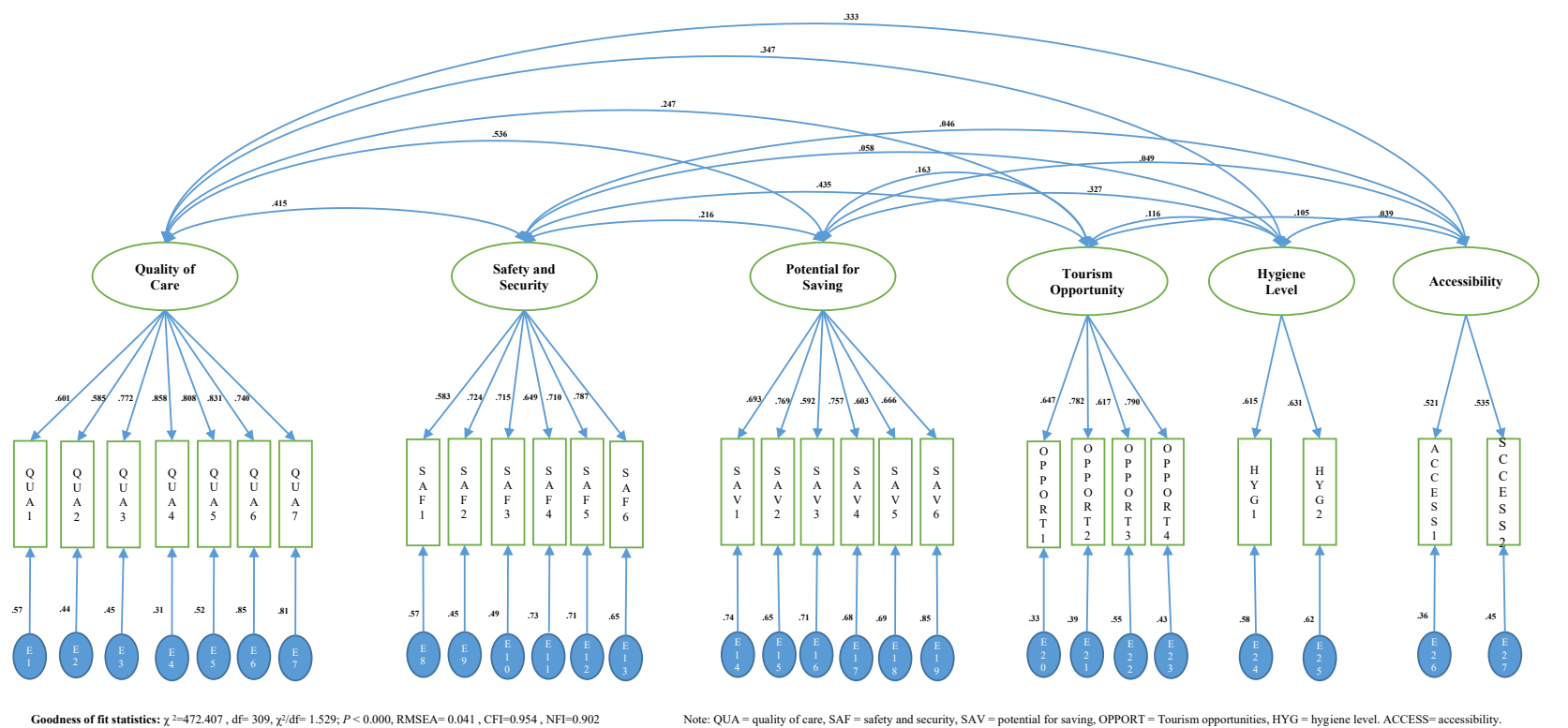

Figure 2. Measurement Model.

5.128, $P<0.01)$, tourism opportunities and destination choice (H4: $\beta$ tourism opportunities $->$ destination choice $=0.302, \mathrm{t}$ $=3.702, P<0.01)$, hygiene level and destination choice $(\mathrm{H} 5: \beta$ hygiene level $->$ destination choice $=0.279, \mathrm{t}=3.146, P<0.01$ ), and accessibility to healthcare and destination choice (H6: $\beta$ accessibility of health care $->$ destination choice $=0.379, \mathrm{t}$ $=4.451, P<0.01)$. All of the six factors, which are important for destination choice, were found to have great good-fit values for the model of the study. As shown in Table 4 and Figure 3, the factors of care quality, security and safety, saving potential, opportunities of tourism, hygiene level, and

Table 4. The Effects of Factors on Destination Choice With Path Analysis ( $N=317$ )

\begin{tabular}{lll}
\hline Effect & Coefficient & t-value \\
\hline Quality of care $\rightarrow$ Affective destination choice & 0.353 & $3.553^{*}$ \\
Safety and security $\rightarrow$ Affective destination choice & 0.379 & $4.568^{*}$ \\
Potential for saving $\rightarrow$ Affective destination choice & 0.278 & $5.128^{*}$ \\
Tourism opportunities $\rightarrow$ Affective destination choice & 0.302 & $3.702^{*}$ \\
Hygiene level $\rightarrow$ Affective destination choice & 0.279 & $3.146^{*}$ \\
Accessibility $\rightarrow$ Affective destination choice & 0.379 & $4.451^{*}$
\end{tabular}

$\overline{R^{2}}$ for quality of care $=0.433 ; R^{2}$ for safety and security $=0.567 ; R^{2}$ for potential saving $=0.166 ; R^{2}$ tourism opportunities $=0.109 ; R^{2}$ for hygiene level $=0.151$; $\mathrm{R}^{2}$ for accessibility $=0.416 . \chi 2=1130.502, \mathrm{df}=508, \chi 2 / \mathrm{df}=2.225, P<0.000$, $\mathrm{RMSEA}=0.063, \mathrm{CFI}=0.902, \mathrm{IFI}=0.929, \mathrm{NNFI}=0.921, \mathrm{AGFI}=0.819$. Note: $* P<0.01$. accessibility significantly influence destination choice for medical tourism. The total variance rates of quality of care, safety and security, potential savings, tourism opportunities, hygiene level, and accessibility were $\mathrm{R}^{2}=43.3 \%, 56.7 \%, 16.6 \%$, $10.9 \%, 15.1 \%$, and $41.6 \%$, respectively. Thus, the proposed model shows the positive structure between the factors that make up the structure of the model.

\section{Discussion}

This study aimed to determine the factors affecting medical tourism destination selection based on the perspectives of

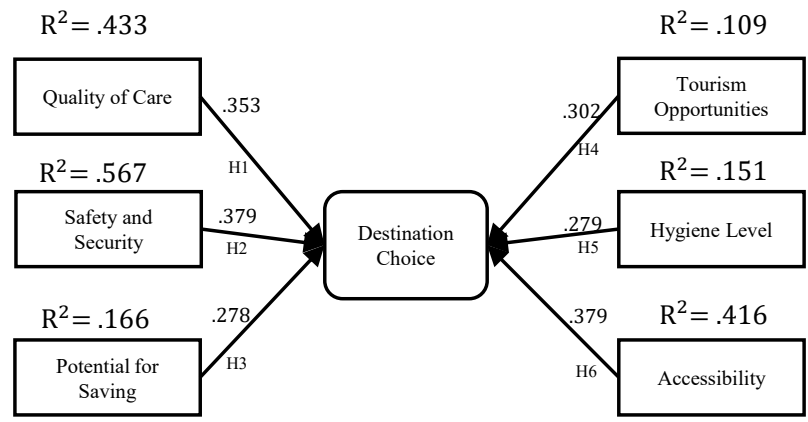

Figure 3. Path Analysis Explaining Factors Influencing Medical Tourism Destination Choice. 
potential medical tourists from different countries who have not previously visited Turkey. This study is the first empirical study of Turkey as a medical tourism destination. The present study used a questionnaire to determine important factors influencing the destination choice of potential medical tourists who are interested and engaged in internal and external information sources about Turkey. Reliability and validity assumptions related to the measurement tool were examined by statistical methods. PA was also applied to identify relationships between the proposed model and the related variables. A causal recipe from affective factors influencing medical tourism destination choices was calculated to investigate salient factors for Turkey as such a destination. The results revealed the validity of the destination choice features, which included six main sub-dimensions: quality care, security and safety, saving potential, opportunities of tourism, hygiene level, and accessibility. The total impact of these six dimensions on destination choice was positive and affective. The results of EFA and CFA analyses indicated that quality of care, safety and security, potential for saving, tourism opportunities, hygiene level, and accessibility to healthcare were necessary factors for medical tourists to engage with Turkey for medical tourism.

According to Fetscherin and Stephano, ${ }^{55}$ two types of factors affect the motivation of potential medical tourists in medical tourism. The first of these is the push factors that are related to countries, such as the health system in the country where potential medical tourists live, the expected wait time for health services, the scope of insurance, or the individual's own preferences. The second type is factors offered by health institutions that attract potential medical tourists, such as saving potential and cultural values. Five of the variables discussed in this study (quality of care, safety and security, potential for saving, tourism opportunities, and hygiene level) fall into the second category and one (accessibility) falls into the first category.

Quality, relatively inexpensive medical treatment facilities, and accessible health services are major reasons for travel from developed to developing countries. ${ }^{25,56}$ The current findings indicate that potential medical tourists are affected by accessibility $(\bar{X}=4.68 \pm 1.073)$, safety and security $(\bar{X}=$ $4: 57 \pm 1.122)$, quality of care $(\bar{X}=4: 39 \pm 1.129)$, hygiene level $(\bar{X}=4.16 \pm 1.381)$, tourism opportunities $(\bar{X}=4.07 \pm 1.447)$, and potential for saving $(\overline{\mathrm{X}}=4.02 \pm 1.540)$. The low cost of health services is an important destination choice criterion; however, it ranks in last place of importance. Although this seems to be an interesting result, it is seen that people prefer health over money; health, quality of care, and accessibility are more important than money in medical tourism.

Most people living in America and Europe either have no health insurance or are not sufficiently covered by health insurance. Thus, American and European citizens participate in medical tourism to access health services more easily and cheaply. Relatively inexpensive healthcare as well as quality healthcare make destinations attractive for these people. ${ }^{2,56-58}$

According to the PA findings, quality of healthcare,

\section{Research Highlights}

\section{What Is Already Known?}

Studies on medical tourism destination selection have included only those who had already traveled and received medical services from a medical tourism destination. Thus, exactly what potential medical tourists expect from medical tourism destinations remained unknown.

\section{What This Study Adds?}

This study examined the expectations of potential firsttime medical tourists from medical tourism destinations. The results will give medical tourism destinations the opportunity to review their strategies based on the expectations of potential customers.

opportunities of tourism, hygiene level, accessibility to health services, and the potential savings provided by medical tourism destinations were found to be effective in the selection of Turkey by potential medical tourists.,

Contrary to popular belief, the results showed that money paid for medical care was not as effective a factor as the quality of medical care; even so, it was found to be an important criterion in choosing a medical tourism destination. With the right marketing and the right mix of promotional activities, Turkey can convert this situation into a business opportunity, as Turkey is considered to have a significant advantage over other competitors.

Potential medical tourists who have negative attitudes healthcare services in their home countries because of unnecessary administrative procedures and long wait times are more highly motivated to engage in medical tourism. They are most concerned with safety and security issues, availability of the desired medical treatment in the country or region of residence, and the quality of the medical care, hygiene level, saving potential, and tourism opportunities provided by the potential medical tourism destination. Considering the internal turmoil and terrorism in many countries in recent years, that participants placed importance on security issues in medical tourism destinations is understandable.

\section{Limitations}

This research focused on the selection of a medical tourism destination by potential medical tourists who had not previously received medical tourism services from Turkey. Not all of the potential medical tourists could be reached because of a predetermined set of parameters.

\section{Conclusion}

This study can serve as a road map for policymakers in medical tourism as well as a starting source for researchers in this academic field. Furthermore, it may help policymakers determine a route for reaching the goals in Turkey's medical tourism strategic action plan. This study is an effective reference for politicians who make Turkey's medical tourism policy. 
This study was conducted in Turkey; however, its results will make a serious contribution to the field of medical tourism in both practice and theory. The results determined that there are many factors affecting the medical tourist's choice of a destination, especially the safe provision of highquality health services, high hygienic levels, easy access to health services, opportunities for saving money, and tourism opportunities.

\section{Authors' Contributions}

The first author collected the data, wrote the manuscript, and made the analysis. The second author interpreted the analysis, reviewed and critiqued the completed study, and wrote the discussion and the conclusion of this manuscript.

\section{Conflict of Interest Disclosures}

The authors declare that they have no conflicts of interest associated with this study.

\section{Ethical Approval \\ Not applicable.}

\section{Funding/Support}

None.

\section{References}

1. Aslan O, Aslan S. Basic Strategies and Implications for Health Tourism in Turkey: A Field Study on Medical Tourism Perceptions of individuals. 1st ed. Istanbul: Form Printing Technologies; 2016.

2. Heung VCS, Kucukusta D, Song H. A conceptual model of medical tourism: implications for future research. J Travel Tour Mark. 2010;27(3):236-251. doi:10.1080/10548401003744677.

3. Han H. The healthcare hotel: Distinctive attributes for international medical travelers. Tour Manag. 2013;36:257-268. doi:10.1016/j. tourman.2012.11.016.

4. Lee HK, Fernando Y. The antecedents and outcomes of the medical tourism supply chain. Tour Manag. 2015;46:148-157. doi:10.1016/j.tourman.2014.06.014.

5. Khafizova L. Importance of Medical Tourism Travel Business Development and Situation in Turkey [thesis]. Istanbul: Istanbul University; 2011.

6. Jotikasthira N. Salient factors influencing medical tourism destination choice [thesis]. East Lismore NSW: Southern Cross University; 2010.

7. Han H, Al-Ansi A, Olya HGT, Kim W. Exploring halal-friendly destination attributes in South Korea: Perceptions and behaviors of Muslim travelers toward a non-Muslim destination. Tour Manag. 2019;71:151-164. doi:10.1016/j.tourman.2018.10.010.

8. Gan LL, Frederick JR. Consumers' attitudes toward medical tourism. SSRN Electronic Journal. 2011. doi:10.2139/ssrn.1837062.

9. Chiu CM, Wang ETG, Fang YH, Huang HY. Understanding customers' repeat purchase intentions in B2C e-commerce: the roles of utilitarian value, hedonic value and perceived risk. Information Systems Journal. 2014;24(1):85-114. doi:10.1111/ j.1365-2575.2012.00407.x.

10. Han H, Hwang J. Investigating healthcare hotel travelers' overall image formation: impact of cognition, affect, and conation. Tour Hosp Res. 2018;18(3):346-356. doi:10.1177/1467358416670936.

11. Ryan C. Halal tourism. Tour Manag Perspect. 2016;19:121-123. doi:10.1016/j.tmp.2015.12.014.

12. Zion Market Research. Medical Tourism Market by Treatment Type (Cancer Treatment, Orthopedic Treatment, Fertility Treatment, Cardiovascular Treatment, Neurological Treatment, and Others): Global Industry Perspective, Comprehensive Analysis, and
Forecast, 2017-2024. https://www.zionmarketresearch.com/. Accessed 18 April 2020.

13. Arya N. Medical Tourism Brings Tons of Business Opportunities in Healthcare Sector. https://www.franchiseindia.com/wellness/ medical-tourism-brings-tons-of-business-opportunities-inhealthcare-sector.12585. Accessed 18 April 2020.

14. Oltulular IO. A research for identifying problems and current situation in medical tourism entrepreneurship: the case of Izmir [thesis]. Balıkesir: Balikesir University; 2018.

15. Sciascia S, Vita DR. The Development of Entrepreneurship Research. Luic Papers Serie Economia Aziendale. 2004;146(19):137.

16. Sheikh R. Tourism entrepreneurship; challenges and possibilities in small tourism businesses [thesis]. Finland: Centria University; 2015.

17. Mun WK, Musa G. Medical tourism: the ethics, regulation and marketing of health mobility. In: Michael H, Publ C, eds. An Investigation of Korean Health Tourists' Behavior: Benefit Sought, Brand Equity, and Intention to Visit. Sweden: Taylor \& Francis; 2013. p. 167-186.

18. Eyler N. A research on determining the intentions of individuals over 50 years of health in the scope of planned behavior; Ankara Case [thesis]. Ankara: Gazi University; 2016.

19. Lee C. Medical Tourism, an innovative opportunity for entrepreneurs. Journal of Asia Entrepreneurship and Sustainability. 2007;3(1):1-12.

20. Connell J. Contemporary medical tourism: conceptualisation, culture and commodification. Tour Manag. 2013;34:1-13. doi:10.1016/j.tourman.2012.05.009.

21. Gholami M, Keshtvarz Hesam Abadi AM, Miladi S, Gholami M. A systematic review of the factors affecting the growth of medical tourism in Iran. Int J Travel Med Glob Health. 2020;8(1):1-12. doi:10.34172/ijtmgh.2020.01.

22. Çapar $\mathrm{H}$. Sources of motivation affecting the decision of potential medical tourists. Journal of Management, Economics and Marketing Research.2019;3(6):252-264.doi:10.29226/TR1001.2019.165.

23. Helble M. The movement of patients across borders: challenges and opportunities for public health. Bull World Health Organ. 2011;89(1):68-72. doi:10.2471/blt.10.076612.

24. Mahmoudifar Y, Tabibi SJ, Nasiripour AA, Riahi L. Factors affecting development of medical tourism industry in West Azerbaijan province of Iran. Int J Health Stud. 2016;2(4):25-31. doi:10.22100/ ijhs.v2i4.181.

25. Ahmed Z, Yeasmeen F. First world healthcare by third world provider: position of Bangladesh. J Health Sci Res. 2016;1(2):2933. doi:10.18311/jhsr/2016/v1/i2/4597.

26. Khan MJ, Chelliah S, Haron MS. Medical tourism destination image formation process: a conceptual model. Int J Healthc Manag. 2016;9(2):134-143. doi:10.1080/20479700.2016.1142046.

27. Lautier M. Export of health services from developing countries: the case of Tunisia. Soc Sci Med. 2008;67(1):101-110. doi:10.1016/j. socscimed.2008.01.057.

28. Snyder J, Dharamsi S, Crooks VA. Fly-by medical care: conceptualizing the global and local social responsibilities of medical tourists and physician voluntourists. Global Health. 2011;7(1):6. doi:10.1186/1744-8603-7-6.

29. Whittaker A. Pleasure and pain: medical travel in Asia. Glob Public Health.2008;3(3):271-290.doi:10.1080/17441690701463936.

30. Moghavvemi S, Ormond M, Musa G, et al. Connecting with prospective medical tourists online: a cross-sectional analysis of private hospital websites promoting medical tourism in India, Malaysia and Thailand. Tour Manag. 2017;58:154-163. doi:10.1016/j.tourman.2016.10.010.

31. Bolton S, Skountridaki L. The medical tourist and a political economy of care. Antipode. 2017;49(2):499-516. doi:10.1111/ anti.12273.

32. Han H, Hyun SS. Customer retention in the medical tourism industry: impact of quality, satisfaction, trust, and price 
reasonableness. Tour Manag. 2015;46:20-29. doi:10.1016/j. tourman.2014.06.003.

33. Guiry M, Vequist DG. South Korea's medical tourism destination brand personality and the influence of personal values. Asia Pacific J Tour Res. 2015;20(5):563-584. doi:10.1080/10941665.20 14.904804.

34. Martínez Álvarez M, Chanda R, Smith RD. The potential for bilateral agreements in medical tourism: a qualitative study of stakeholder perspectives from the UK and India. Global Health. 2011;7:11. doi:10.1186/1744-8603-7-11.

35. Rodrigues $\mathrm{H}$, Brochado A, Troilo M, Mohsin A. Mirror, mirror on the wall, who's the fairest of them all? a critical content analysis on medical tourism. Tour Manag Perspec. 2017;24:16-25. doi:10.1016/j.tmp.2017.07.004.

36. García-Altés A. The development of health tourism services. Ann Tour Res. 2005;32(1):262-266. doi:10.1016/j.annals.2004.05.007.

37. Jones CA, Keith LG. Medical tourism and reproductive outsourcing: the dawning of a new paradigm for healthcare. Int J Fertil Womens Med.2006;51(6):251-255.

38. Lin $\mathrm{CH}$, Morais DB, Kerstetter DL, Hou JS. Examining the role of cognitive and affective image in predicting choice across natural, developed, and theme-park destinations. J Travel Res. 2007;46(2):183-194. doi:10.1177/0047287507304049.

39. White CJ. Destination image: to see or not to see? Int J Contemp Hosp Manag.2004;16(5):309-314.doi:10.1108/09596110410540285.

40. Anderson JC, Gerbing DW. Structural equation modeling in practice: a review and recommended two-step approach. Psychol Bull. 1988;103(3):411-423. doi:10.1037/0033-2909.103.3.411.

41. Ford JK, MacCallum RC, Tait M. The application of exploratory factor analysis in applied psychology: a critical review and analysis. Pers Psychol. 1986;39(2):291-314. doi:10.1111/j.1744-6570.1986. tb00583.x.

42. George D, Mallery P. SPSS for Windows. Needham Heights, MA: A Pearson Education; 2001.

43. Black K. Business Statistics: Contemporary Decision Making. 6th ed. John Wiley \& Sons; 2010.

44. Saunders M, Lewis P, Thornhill A. Research Methods for Business
Students. 6th ed. Pearson Education Limited; 2012.

45. Islamoglu AH, Alnıacik U. Research Methods in Social Sciences. 5th ed. Istanbul: Beta Basım A.Ş.; 2016.

46. Sharma S. Applied Multivariate Techniques. New York: John Wiley \& Sons Inc; 1996.

47. Hair JF, Black WC, Babin BJ, Anderson RE, Tatham RL. Multivariate Data Analysis. Upper Saddle River, NJ: Prentice Hall; 1998.

48. Tabachnick BG, Fidell LS. Using Multivariate Statistics. 6th ed. Pearson; 2014.

49. Prentice R. Evocation and experiential seduction: updating choicesets modelling. Tour Manag. 2006;27(6):1153-1170. doi:10.1016/j. tourman.2005.11.008.

50. Li M, Cai LA. The effects of personal values on travel motivation and behavioral intention. J Travel Res. 2012;51(4):473-487. doi:10.1177/0047287511418366.

51. Nunnally JC. Psychometric theory. 2nd ed. New York, NY: McGraw-Hill; 1978.

52. Bagozzi RP, Yi Y. On the evaluation of structural equation models. J Acad Mark Sci. 1988;16(1):74-94. doi:10.1007/bf02723327.

53. Fetscherin $M$, Stephano RM. The medical tourism index: scale development and validation. Tour Manag. 2016;52:539-556. doi:10.1016/j.tourman.2015.08.010.

54. Moghimehfar F, Nasr-Esfahani MH. Decisive factors in medical tourism destination choice: a case study of Isfahan, Iran and fertility treatments. Tour Manag. 2011;32(6):1431-1434. doi:10.1016/j. tourman.2011.01.005.

55. Wang YH. Expectation, service quality, satisfaction, and behavioral intention-evidence from Taiwan's medical tourism industry. Advances in Management and Applied Economics. 2017;7(1):1-16.

56. Ganguli S, Ebrahim AH. A qualitative analysis of Singapore's medical tourism competitiveness. Tour Manag Perspec. 2017;21:74-84. doi:10.1016/j.tmp.2016.12.002.

57. Debata BR, Patnaik B, Mahapatra SS, Sree K. Interrelations of service quality and service loyalty dimensions in medical tourism: a structural equation modelling approach. Benchmarking: An International Journal. 2015;22(1):18-55. doi:10.1108/BIJ-04-20130036 